\title{
Anion-specific sulfur isotope analysis by liquid chromatography coupled to multicollector ICPMS
}

\author{
Mathieu Martinez ${ }^{1}$, Jose Ignacio Garcia-Alonso ${ }^{2}$, Corinne Parat ${ }^{1}$, Jorge Ruiz Encinar², Isabelle Le \\ Hécho*1 \\ ${ }^{1}$ CNRS / Univ. Pau \& Pays de l'Adour / E2S UPPA, Institut des Sciences Analytiques et de Physico-Chimie pour l'Envi- \\ ronnement et les Matériaux, UMR 5254, 2 avenue Pierre Angot, Pau, 64000, France \\ 2Department of Physical and Analytical Chemistry, University of Oviedo, Julián Clavería 8, 33006, Oviedo, Spain
}

\begin{abstract}
An accurate method has been developed to measure, in a single analytical run, $\delta^{34} S$ in sulfite, sulfate and thiosulfate in water samples by liquid chromatography combined with multicollector inductively coupled plasma mass spectrometry (MC-ICPMS). The method is based on the anionic exchange separation of sulfur species prior to their online isotope ratio determination by MC-ICPMS. Mass bias correction was accomplished by a novel approach based on the addition of an internal sulfur-containing standard to the sample. This innovative approach was compared to the sample-standard bracketing procedure. On-column isotopic fractionation was observed and therefore corrected by external calibration. Isotopic ratios were calculated by linear regression slope (LRS), an advantageous method for transient signals, leading to a combined uncertainty of $\delta^{34} \mathrm{~S}$ below $0.25 \%$ and a reproducibility below $0.5 \%$ or the injection of $1 \mu \mathrm{g}$ of S. The method was successfully applied to the measurement of $\delta^{34} \mathrm{~S}$ in synthetic solutions and environmental water samples. Matrix effects leading to $\delta^{34} \mathrm{~S}$ overestimation were observed for sulfate in some samples with high sodium/sulfate mass ratios. The developed analytical procedure simplifies the $\delta^{34} \mathrm{~S}$ analysis of liquid environmental samples since preparation steps are no longer required and allows the analysis of several sulfur-containing species in a single run.
\end{abstract}

Sulfur is a key component of many natural environments, is involved in natural biogeochemical processes ${ }^{1,2}$ and can play an important role in the biodegradation of contaminants. ${ }^{3}$ Sulfur is highly reactive and can exist in different redox states (-II to + VI). Both reduction and oxidation of sulfur lead to large isotopic fractionation effects, which result in changes in the isotopic composition $\left(\delta^{34} S\right)$ of individual sulfur species (sulfite, sulfate, thiosulfate, elemental sulfur, and tetrathionate). ${ }^{4-7}$ Thus, measurement of the sulfur isotopic composition of specific molecules is potentially very useful for understanding the isotope fractionation associated with the numerous redox reactions that characterize the modern sulfur cycle since the results combine molecular and isotopic information associated with fractionation mechanisms.

The conventional approach for sulfur isotopic analysis is based on the conversion of a sample to $\mathrm{SO}_{2}$ by combustion in an elemental analyzer (EA) and determination of the ${ }^{32} \mathrm{~S} /{ }^{34} \mathrm{~S}$ ratio in an isotope ratio mass spectrometer (IRMS). This kind of analysis is restricted to bulk materials, and 10 to $50 \mu \mathrm{g}$ of sulfur are needed, consequently, for water samples with low sulfur concentration, large sample volumes (> $5 \mathrm{~L})$ are required. ${ }^{8,9}$ Furthermore, the determination of $\delta^{34} \mathrm{~S}$ for dissolved individual species via this method requires a tedious and time-consuming sample preparation. Isolation of each individual species can be achieved through complex and laborious steps that can lead to isotopic fractionation and contamination. Sulfate is generally recovered by precipitation with barium $\left(K_{\mathrm{s}}\left(\mathrm{BaSO}_{4}\right)=1.08 \cdot 10^{-10}\right)$, but if the sample also contains sulfite, the sulfite will also coprecipitate $\left(K_{\mathrm{s}}\left(\mathrm{BaSO}_{3}\right)=5.0 \cdot 10^{-10}\right) .{ }^{10}$

In recent years, it has been demonstrated that precise $(0.1$ $1 \% 0$ ) measurements of $\delta^{34} \mathrm{~S}$ can be achieved by multicollector inductively coupled plasma mass spectrometry (MCICPMS) with sulfur sample requirements at the $\mu \mathrm{g}$ level. ${ }^{11-15}$ These methods have highlighted the feasibility of bulk analysis of liquid samples by direct measurement with MCICPMS. Recently, Zakon et al. ${ }^{16}$ combined ion chromatography with MC-ICPMS for the analysis of $\delta^{34} \mathrm{~S}, \delta^{81} \mathrm{Br}$, and $\delta^{37} \mathrm{Cl}$ in individual anionic species and illustrated the potential for anion-specific analysis of inorganic sulfur by analyzing a solution of sulfate and thiosulfate. In this study, the objective was to develop a method for the online determination of $\delta^{34} \mathrm{~S}$ in sulfite, sulfate and thiosulfate by coupling liquid chromatography (LC) to MC-ICPMS. Conventionally, mass bias is corrected by sample-standard bracketing, which can be done with the same ion (compound-specific bracketing, CSB) or different species (compound-unspecific bracketing, CUB ${ }^{17}$ as the analyte. In this study, we proposed a new approach based on the direct addition of an internal standard (trimethylsulfoxide, TMSO) to the sample. In addition, isotope ratios were calculated by the linear regression slope (LRS), a strategy originally developed by Fietzke et al. ${ }^{18}$ for Sr isotope analysis by laser ablation MC-ICPMS and further applied to gas chromatography MC-ICPMS ${ }^{17}$ and LCMC-ICPMS. ${ }^{19-21}$ LRS analysis is a suitable data treatment protocol for the determination of isotope ratios with transient signals which improves the accuracy and precision of 
isotopic ratios over those of peak area integration and point-by-point computation. LRS analysis is an advantageous method since no background subtraction is needed, which is of great importance in the case of sulfur, which is present in trace amounts in the mobile phases and ICP gases used. In this work, we used this new approach for sulfur isotopic ratios for the first time, and efforts were made to minimize uncertainties of the LRS calculations by optimizing the peak zones used for these calculations.

\section{EXPERIMENTAL SECTION}

Reagents, Standards and Solutions. Ultrapure water $(18.2 \mathrm{M} \Omega \mathrm{cm}$ ) obtained from a Milli-Q system (Millipore Co., Bedford, MA, USA) was used to prepare all solutions and for sample dilution. The reference materials IAEA-S3 $\left(\mathrm{Ag}_{2} \mathrm{~S}\right)$ and IAEA-S4 (elemental S) were purchased from the International Atomic Energy Agency (IAEA, Austria). Sulfamic acid $\left(\mathrm{H}_{3} \mathrm{NO}_{3} \mathrm{~S}\right)$, used as an in-house reference material, was purchased from OEA labs (UK). Each reference material was acid digested in a microwave (Ethos Touch Control, Milestone, Italy) with high-purity 70\% nitric acid (J.T. Baker, UK) and subsequently diluted with ultrapure water, resulting in a sulfate solution.

Analytical standards of sulfite, sulfate and thiosulfate were purchased from different manufacturers to assess their variability. From Sigma-Aldrich (Germany), we purchased ammonium sulfate (>99\%), ammonium thiosulfate (>98\%), sodium thiosulfate pentahydrate (ACS), sodium sulfite (analytical standard), sodium sulfite (BioUltra), and sodium sulfite (ACS). Sodium sulfate ( $>99 \%)$ was purchased from VWR Prolabo (France), while sodium thiosulfate pentahydrate (ACS) was also purchased from Fluka (Germany) and Probus (Spain). Additional standards of sodium sulfate and sodium sulfite (Reag. Ph Eur) were purchased from Merck (Germany).

Synthetic solutions were prepared with sulfite, sulfate and thiosulfate to optimize the method parameters and to compare the results with those obtained by EA-IRMS; the solution compositions are summarized in Table 1 . A total of $1 \%$ of formaldehyde was added to the sulfite stock solutions to prevent oxidation.

Table 1. Composition of Synthetic Solutions. The concentration of each anion is $10 \mu \mathrm{g} / \mathrm{g}$ of $S$.

\begin{tabular}{|c|c|c|c|}
\hline Name & Sulfite & Sulfate & Thiosulfate \\
\hline $\begin{array}{l}\text { Solu- } \\
\text { tion } 1\end{array}$ & $\begin{array}{l}\mathrm{Na}_{2} \mathrm{SO}_{3}(\mathrm{An} . \\
\text { std.) Sigma- } \\
\text { Aldrich }\end{array}$ & $\begin{array}{l}\left(\mathrm{NH}_{4}\right)_{2} \mathrm{SO}_{4} \\
(>99 \%) \\
\text { Sigma-Aldrich }\end{array}$ & $\begin{array}{l}\left(\mathrm{NH}_{4}\right)_{2} \mathrm{~S}_{2} \mathrm{O}_{3} \\
(>98 \%) \\
\text { Sigma-Aldrich }\end{array}$ \\
\hline $\begin{array}{l}\text { Solu- } \\
\text { tion } 2\end{array}$ & $\begin{array}{l}\mathrm{Na}_{2} \mathrm{SO}_{3} \\
\text { (BioUltra) } \\
\text { Sigma-Al- } \\
\text { drich }\end{array}$ & $\begin{array}{l}\mathrm{Na}_{2} \mathrm{SO}_{4} \\
\text { (ACS) } \\
\text { VWR Prolabo }\end{array}$ & $\begin{array}{l}\mathrm{Na}_{2} \mathrm{~S}_{2} \mathrm{O}_{3} .5 \mathrm{H}_{2} \mathrm{O} \\
\text { (ACS) } \\
\text { Sigma-Aldrich }\end{array}$ \\
\hline $\begin{array}{l}\text { Solu- } \\
\text { tion } 3\end{array}$ & $\begin{array}{l}\mathrm{Na}_{2} \mathrm{SO}_{3}(\mathrm{ACS}) \\
\text { Sigma-Al- } \\
\text { drich }\end{array}$ & $\begin{array}{l}\text { IAEA-S4 } \\
\text { (mineralized) } \\
\text { IAEA }\end{array}$ & $\begin{array}{l}\mathrm{Na}_{2} \mathrm{~S}_{2} \mathrm{O}_{3} .5 \mathrm{H}_{2} \mathrm{O} \\
\text { Fluka }\end{array}$ \\
\hline $\begin{array}{l}\text { Solu- } \\
\text { tion } 4\end{array}$ & $\begin{array}{l}\mathrm{Na}_{2} \mathrm{SO}_{3} \\
\text { (Reag. Ph } \\
\text { Eur) Merck }\end{array}$ & $\begin{array}{l}\mathrm{Na}_{2} \mathrm{SO}_{4} \text { (Reag. } \\
\text { Ph Eur) } \\
\text { Merck }\end{array}$ & $\begin{array}{l}\mathrm{Na}_{2} \mathrm{~S}_{2} \mathrm{O}_{3} .5 \mathrm{H}_{2} \mathrm{O} \\
\text { (ACS) Probus }\end{array}$ \\
\hline
\end{tabular}

Finally, formaldehyde (ACS, 37\%), ammonium hydroxide $(30 \%)$, ammonium nitrate ( $>99.5 \%)$, trimethylsulfoxonium chloride (TMSO) and silicon standard solution $(1000 \mu \mathrm{g} / \mathrm{g}$, TraceCERT) were obtained from Sigma-Aldrich (Germany).

Natural spring and river water samples originating from the Sivas Basin, Turkey, and described elsewhere ${ }^{22}$ were used for comparison and validation purposes.

Instrumentation. The multicollector inductively coupled plasma mass spectrometer used was a Neptune Plus from Thermo-Fisher Scientific (Bremen, Germany) operated at medium resolution $(\Delta \mathrm{m} / \mathrm{m}=5000)$ to resolve polyatomic interferences $\left({ }^{16} \mathrm{O}_{2}{ }^{+}\right.$and ${ }^{16} \mathrm{O}^{18} \mathrm{O}^{+}$on ${ }^{32} \mathrm{~S}$ and ${ }^{34} \mathrm{~S}$, respectively) as previously described ${ }^{15}$. The instrument was equipped with 9 Faraday cups. The sample introduction system was a Micromist nebulizer and a Scott double-pass spray chamber. The sample gas flow, torch position and ion lens settings were optimized on a daily basis to obtain maximum sensitivity. The cup configuration was set to include ${ }^{29} \mathrm{Si}$ and ${ }^{30} \mathrm{Si}$ for possible internal mass bias correction. The axial Faraday cup (C) was fixed at mass 31.065 (amu) for interference-free measurements of ${ }^{29} \mathrm{Si}(\mathrm{L} 4),{ }^{30} \mathrm{Si}$ (L1), ${ }^{32} \mathrm{~S}(\mathrm{H} 1)$, and ${ }^{34} \mathrm{~S}$ (H4) isotopes as previously described by Martínez-Sierra et al. ${ }^{11}$ Unfortunately, the internal mass bias correction procedure using silicon failed and hence is not described in this paper. Although the measure of ${ }^{33} \mathrm{~S}$ is possible it has not been attempted. The measurement of ${ }^{36} \mathrm{~S}$ is not possible due to unresolved interferences of ${ }^{36} \mathrm{Ar}$. Liquid chromatography separations were performed with a Surveyor LC Pump Plus (ThermoFisher Scientific, Bremen, Germany) using an anion exchange column Dionex IonPac AS15 ( $2 \times 250 \mathrm{~mm})$ and a guard column AG15 $(2 \times 50 \mathrm{~mm})$ (ThermoFisher Scientific, Bremen, Germany). The stationary phase consisted of silica bonded with alkanol quaternary ammonium groups. The particle size was $7.5 \mu \mathrm{m}$. All separations were performed at room temperature with an eluent consisting of 40-100 mM ammonium nitrate (gradient elution) and $0.1 \%$ formaldehyde at pH 7 (adjusted with 30\% $\mathrm{NH}_{4} \mathrm{OH}$ ). Samples and standards were diluted into the mobile phase before injection using a six-way rheodyne valve in the chromatographic system. The instrumental operating conditions and data acquisition parameters are listed in Table S-1 in the supporting information.

Calculation of Isotopic Ratios $\left({ }^{34} S /{ }^{32} S\right)$ and Delta Values $\left(\boldsymbol{\delta}^{34} \boldsymbol{S}\right)$. Sulfur isotope ratios $\left({ }^{34} \mathrm{~S} /{ }^{32} \mathrm{~S}\right)$ were calculated by linear regression slope (LRS). ${ }^{17,18,21}$ The regression line is described by the following:

Equation 1: $\quad y=a x+b$

where $y$ and $x$ represent the measured intensities (in V) of ${ }^{34} \mathrm{~S}$ and ${ }^{32} \mathrm{~S}$, respectively; $a$ is the slope of the linear regression and corresponds to the isotopic ratio ${ }^{34} \mathrm{~S} /{ }^{32} \mathrm{~S}$ as shown by Frietzke et $\mathrm{al}^{18}$; and $b$ is the intercept of the line. The measurement uncertainty of isotopic ratios corresponds to the standard deviation of the slope computed from at least 1000 data points ( $100 \%$ of the peak).17,18,21

The delta value $\left(\delta^{34} S\right)$ is always expressed against the VCDT scale in \%o and was calculated against the standard as follows:

Equation 2:

$$
\delta^{34} S=\left(\left(\frac{{ }^{34} S}{{ }^{32} S}\right)_{\text {Sample }} /\left(\frac{{ }^{34} S}{{ }^{32} S}\right)_{W S}\right) \times\left(\delta^{34} S_{W S}+1\right)-1
$$


where WS is the working standard.

The combined uncertainty $\left(\mathrm{u}_{\mathrm{c}}\right)$ of $\delta^{34} \mathrm{~S}$ is calculated following the Kragten spreadsheet method, ${ }^{23}$ as recommended by Eurachem guideline ${ }^{24}$. The Kragten spreadsheet method, based on the general error propagation formula, is a numerical method for calculating the combined uncertainty from measurement uncertainties. The contributors to $u_{c}$ are the measurement uncertainty of sulfur isotope ratios $\left({ }^{34} \mathrm{~S} /{ }^{32} \mathrm{~S}\right)$ values obtained for both the working standard and the analyte. A coverage factor of $\mathrm{k}=2$ was used for an approximate level of confidence of $95 \%$.

Four methods for the measurement of $\delta^{34} \mathrm{~S}$ were compared for accuracy and uncertainties: (1) Compound unspecific bracketing (CUB), where the standard is the average of two measurements of TMSO conducted before and after each sample; (2) internal standardization (IS), where the standard (TMSO) is added to the sample solution as an internal standard; (3) internal standardization combined with a correction by external calibration (ISEC), where $\delta^{34} S$ is first calculated with the IS method and standards of each anion are analyzed throughout the analytical procedure to build a calibration curve for each anion and then used to correct the $\delta^{34} \mathrm{~S}$ values. This method is an analogue of the data treatment usually performed when measuring $\delta^{34} \mathrm{~S}$ by EAIRMS ${ }^{25}$; and (4) Compound specific bracketing (CSB), where the standard is the same anion as the sample and consists of the average calculation of two measurements conducted before and after each sample.

\section{RESULTS AND DISCUSSION}

Chromatographic Operating Conditions. As reported by Lin \& Jiang, ${ }^{26}$ suitable separation of sulfite, sulfate and thiosulfate can be achieved using a mobile phase of ammonium nitrate $(60 \mathrm{mM})$ and formaldehyde $(0.1 \%)$. In this method, sulfite reacts with formaldehyde to form hydroxymethanesulfonate, a more stable species. ${ }^{27}$ In this study, the previously developed method was modified using a gradient elution (40-100 $\mathrm{mM} \mathrm{NH}_{4} \mathrm{NO}_{3}$ ) to include TMSO and obtain the maximum sensitivity for all ions while maintaining baseline peak separation, as peak separation is better for measuring $\delta^{34} \mathrm{~S}$. A typical chromatogram is shown in Figure 1. Using the working parameters listed in Table S1, peak areas of $24,26,27$ and 26 V.s per $1 \mu \mathrm{g}$ of injected S were obtained for TMSO, sulfite, sulfate and thiosulfate, respectively. Since liquid chromatography enables separation of the four ions in 20 minutes, the isotope ratios of each ion can be measured, and TMSO can be used for internal standardization.

Mass Bias Correction. Different approaches to correct for mass bias and simultaneously measure the $\delta^{34} \mathrm{~S}$ values of sulfite, sulfate and thiosulfate in water samples were investigated. Three different solutions (1,2 and 3) containing the three anions (10 $\mu \mathrm{g} / \mathrm{g}$ of $\mathrm{S}$ for each anion) from different manufacturers (Table 1) were analyzed to evaluate the $\delta^{34} \mathrm{~S}$ measurement uncertainties and accuracy of the four different approaches previously described in the experimental section. Internal correction based on the measurement of the ${ }^{30} \mathrm{Si} /{ }^{29} \mathrm{Si}$ ratio in silicon added to the mobile phase $(10$ $\mu \mathrm{g} / \mathrm{g})$ was also evaluated. But this procedure resulted in very high errors $(>4 \% 0)$ in the measured $\delta^{34}$ S values due to the highly variable ${ }^{30} \mathrm{Si} /{ }^{29} \mathrm{Si}$ ratio (see Figure S-1) and was therefore abandoned. As an alternative, we selected TMSO for addition to each solution for IS measurements.

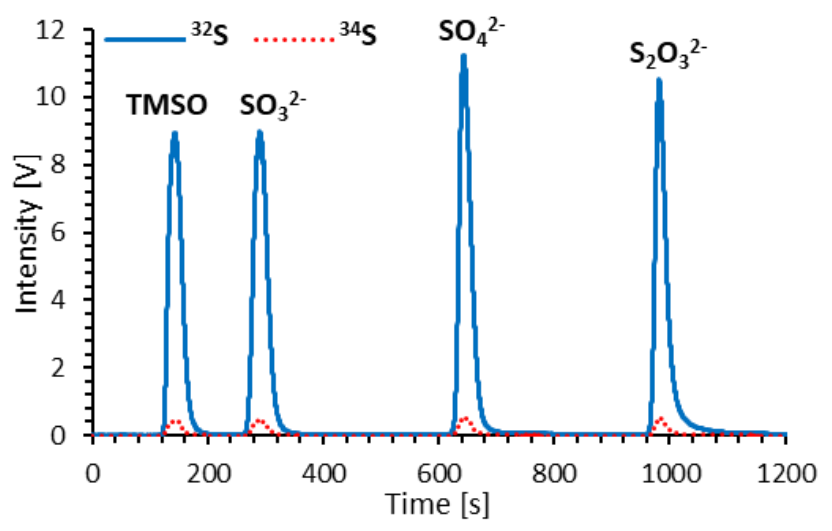

Figure 1. LC-MC-ICPMS analysis of a solution of $\mathrm{Na}_{2} \mathrm{SO}_{3}$, $\left(\mathrm{NH}_{4}\right)_{2} \mathrm{SO}_{4}$ and $\left(\mathrm{NH}_{4}\right)_{2} \mathrm{~S}_{2} \mathrm{O}_{3}$ with TMSO as internal standard (10 $\mu \mathrm{g} / \mathrm{g}$ of $\mathrm{S}$ for each species).

Each compound was previously analyzed by EA-IRMS to determine its $\delta^{34}$ S. Figure 2 shows $\delta^{34} \mathrm{~S}$ values measured by EA-IRMS for the different species in all analyzed solutions and by LC-MC-ICPMS with different measurement methods. A peak window of $100 \%$ was used for LRS calculations, as is common in other works. ${ }^{17,20}$ For the three anions, the results measured by IS and CUB were not significantly different (within $0.2 \% 0$ ) and the standard deviations of replicate analysis ( $n=3$ for Solution $1, n=2$ for Solutions 2 and 3) are not degraded between CUB and IS. This is in line with the work of Guéguen et al. ${ }^{28}$ who noted that mass bias correction with a single standard injection provides similar performance $(0.05 \%$ o to $0.28 \%$ o for Samarium ratios) to that of a correction with two injected standards $(0.04 \%$ to $0.61 \%$ for Neodymium ratios). The results obtained with IS and CUB are not significantly different from those obtained by EA-IRMS (within $0.6 \% 0,0.4 \%$ and $0.9 \%$ respectively for sulfite, sulfate and thiosulfate) except for sulfate and thiosulfate in Solution 3. However, in this work, we noticed a systematic positive bias for thiosulfate $\delta^{34} S$ (between 0.32 and $0.97 \%$ ) when measured with the IS and CUB methods. Some authors have noticed that isotopic fractionation can occur over the course of chromatographic separation, leading to a variation of isotopic ratio during peak elution. ${ }^{20,29,30}$ In this study, the chromatographic separation run took 20 minutes, and on-column isotopic fractionation could be a possible explanation for the observed bias on thiosulfate $\delta^{34} \mathrm{~S}$ value. Figure 3 shows the signal of ${ }^{32} \mathrm{~S}$ and the ${ }^{34} \mathrm{~S} /{ }^{32} \mathrm{~S}$ isotopic ratio in function of the elution time for TMSO, sulfite, sulfate and thiosulfate. No drift was observed on the ${ }^{34} \mathrm{~S} /{ }^{32} \mathrm{~S}$ isotopic ratio for the TMSO. Conversely, a significant drift of the isotopic ratio was observed for the three anions. The ${ }^{34} \mathrm{~S} /{ }^{32} \mathrm{~S}$ ratios decrease through elution, suggesting an isotopic fractionation with a faster elution of heavy isotopes. The amplitude of the drift is $0.4 \%$ for sulfite, $1.4 \%$ for sulfate and $2.0 \%$ for thiosulfate. Therefore, the amplitude of the drift increases with the retention time. The difference in retention time and thus in the drift amplitude between TMSO and thiosulfate could explain the observed bias on the thiosulfate $\delta^{34}$ S values. To investigate this phenomenon, we analyzed a solution of sulfate $\left(\left(\mathrm{NH}_{4}\right)_{2} \mathrm{SO}_{4}\right)$ and thiosulfate 
$\left(\left(\mathrm{NH}_{4}\right)_{2} \mathrm{~S}_{2} \mathrm{O}_{3}\right)$ using four different elution gradients with the same batch of mobile phase to obtain different retention times for the same anions. If isotopic fractionation during elution does not take place, the retention time should not affect $\delta^{34} S$. The results for $\delta^{34} S$ measured by IS are reported in Table 2. For both sulfate and thiosulfate, the measured $\delta^{34} S$ increased with retention time, by up to $0.7 \%$ and $1 \%$, respectively. Therefore, the observed bias on the $\delta^{34} S$ value depends on retention time. This suggests that a correction with an anion eluted at the same retention time is required to avoid the bias on $\delta^{34} \mathrm{~S}$.

To correct the $\delta^{34} \mathrm{~S}$ bias induced by on-column isotopic fractionation, anion-specific calibration is required; thus, we coupled the IS method with an anion-specific external calibration method (ISEC). The first replicate of each synthetic solution was considered as the "standard", and its $\delta^{34} \mathrm{~S}$, measured previously by EA-IRMS, was used as a reference value to create a calibration curve for each species. The linear regression coefficients of the calibration curves were then used to correct the data. With this method, there is no systematic error. The results for the three anions are not significantly different from those obtained by EA-IRMS (within $0.2 \%, 0.4 \%$ and $0.3 \%$ respectively for sulfite, sulfate and thiosulfate) (Figure 2).

CSB was also evaluated. As highlighted in Figure 2, standard deviations for sulfite and sulfate were larger with CSB (0.2$0.3 \%$ and $0.6-0.9 \%$, respectively) than with ISEC (0.01$0.2 \%$ and $0.3-0.6 \%$, respectively). Also, the Figure 2 shows that the accuracy is degraded with the CSB in comparison to the ISEC method. Furthermore, the $\delta^{34} S$ of sulfate in Solution 3 appears significantly different from the certified value. In this solution the sulfate comes from mineralized elemental sulfur (IAEA-S4), which has a very different matrix than the bracketing standards. The correction of mass bias by sample standard bracketing requires no difference in matrix between the standard and sample because the matrix can affect the mass bias inside the mass spectrometer. ${ }^{31}$ Consequently, we assume that such error on $\delta^{34} S$ is likely due to such matrix effects. In contrast, when using ISEC, mass bias and on-column isotopic fractionation are corrected with an internal standard added to the sample and anion-specific external calibration, respectively, which makes ISEC a robust method.
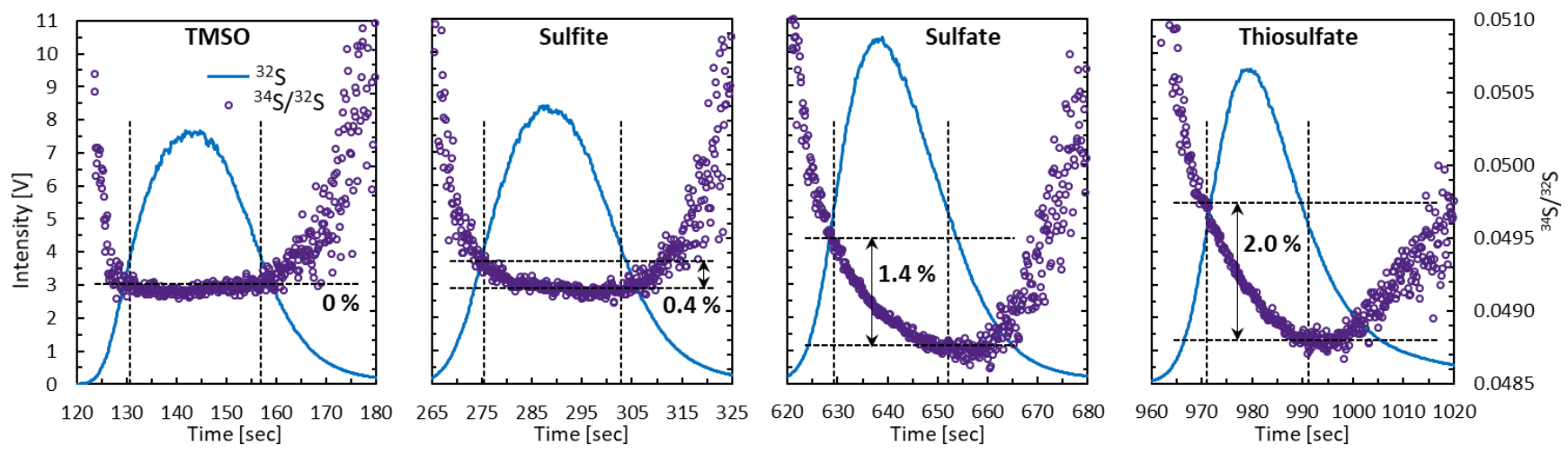

Figure 3. Measured ${ }^{32} \mathrm{~S}$ signal (Solution 1, $10 \mu \mathrm{g} / \mathrm{g}$ of $\mathrm{S}$ for each ion) by LC-MC-ICPMS and ${ }^{34} \mathrm{~S} /{ }^{32} \mathrm{~S}$ isotopic ratio across elution of TMSO, sulfite, sulfate and thiosulfate. The approximate amplitude of the isotopic drift was estimated by the variation of the isotopic ratios between the two horizontal lines (at elution times corresponding to $50 \%$ of the signal maximum for ${ }^{32} \mathrm{~S}$ ). 
Our results demonstrate that ISEC is the most accurate and robust method to simultaneously measure $\delta^{34} S$ in sulfite, sulfate and thiosulfate. Thus, this approach was chosen and applied for sample analyses.

Optimization of the Peak Zone for LRS Calculation. It has been demonstrated that better results are obtained when LRS is performed on the full peak zone (100\%) rather than smaller zones and that the standard deviation of the measured isotopic ratio depends on the regression coefficient $\left(\mathrm{R}^{2}\right)$ of the linear function. ${ }^{17}$ In this study, we evaluated the possibility of calculating the isotopic ratio with larger peak zones, up to $300 \%$ of the peak (Figure 4C). Furthermore, we determined the peak zone between $100 \%$ and $300 \%$ of the peak providing the maximum $\mathrm{R}^{2}$ of the linear function and the peak zone providing the minimum slope standard deviation by an iterative algorithm implemented as a Visual Basic code within Microsoft Excel (more details in SI). The different isotope ratio calculation methods were applied to the data obtained from previous analysis of the synthetic solutions to recalculate $\delta^{34}$ S values. To obtain a simple estimator of accuracy for each peak zone, the root-mean-square error (RMSE) expressed in \%o was calculated as follows:

Equation 3:

$$
R M S E=\sqrt{\sum\left(\delta^{34} S_{E A-I R M S}-\delta^{34} S_{L C-M C-I C P M S}\right)^{2} / n}
$$

where $\delta^{34} S_{\text {EA-IRMS }}$ and $\delta^{34} S_{\text {LC-MC-ICPMS }}$ are the $\delta^{34}$ S values determined by EA-IRMS and LC-MC-ICPMS, respectively, and $n$ is the number of samples. Here, $\mathrm{n}=7$ for each anion in each calculation. RMSE takes into account the differences $\left(\delta^{34} S_{E A-I R M S}-\delta^{34} S_{L C-M C-I C P M S}\right)$ of a whole sample list, allowing a simple comparison of accuracy among different data treatments. For each peak zone, one RMSE per anion were calculated (see Figure 4A). For sulfite and thiosulfate, there was no significant change in RMSE whatever the peak zone tested; in contrast, for sulfate, RMSE decreased from $0.351 \%$ o for a peak zone of $100 \%$ to $0.300 \%$ o for a peak zone of $300 \%$ and $0.296 \%$ when the peak zone is selected to have the lowest slope standard deviation (zone for $\mathrm{u}_{\text {slope }}$ $\min$ ). Considering the three anions, the slope standard deviation minimization provided the most accurate calculation of $\delta^{34} \mathrm{~S}$ values, as this condition led to the minimum RMSE.

The mean combined uncertainties $\left(u_{c}\right)$ for each anion were calculated (Figure 4B). As expected, the combined uncertainty decreased with the expansion of the peak zone, the lowest values being obtained for a peak zone of 300\% and for a peak zone selected by slope standard deviation minimization. Thus, $\mathrm{u}_{\mathrm{c}}$ decreases from $0.12,0.34$ and $0.38 \%$ when $100 \%$ of the peak is taken to $0.09,0.18$ and $0.23 \%$, with peak zones of $300 \%$ or slope standard deviation minimization, respectively for sulfite, sulfate and thiosulfate. These results are not surprising since the contributors to $\mathrm{u}_{\mathrm{c}}$ are the slope standard deviations (corresponding to ${ }^{34} \mathrm{~S} /{ }^{32} \mathrm{~S}$ ) of the internal standard and of the analyte (equation 1) and thus minimizing the slope standard deviation leads to a minimized $u_{c}$. These results suggest that expanding the peak zone for LRS calculation, including baseline points and selecting the peak zone in order to maximize the $\mathrm{R}^{2}$ or minimize the slope standard deviation of the linear function, improves the accuracy of the measurements and leads to lower combined uncertainties. Minimization of slope standard deviation works best. The inclusion of baseline points in the LRS calculation leads to a better estimation of the $b$ terms of equation 1 ( $b$ is correlated with the background signal) and consequently to a better estimation of the isotope ratio. Slope standard deviation minimization was selected to define the peak zones for LRS calculations since this approach improves accuracy and decreases significantly the combined uncertainty. Here, we demonstrated that LRS taken together with ISEC leads to a combined uncertainty lower than $0.25 \%$ for anion-specific measurements of inorganic sulfur; this result is comparable to those obtained by Hanousek et al.12, i.e., $0.3 \%$ for sulfate $\delta^{34} \mathrm{~S}$ measurement by MC-ICPMS. Standard deviations of replicate injections $(\mathrm{n}=3)$ of $0.20 \%, 0.37 \%$ and $0.56 \%$ were obtained for sulfite, sulfate and thiosulfate, respectively, which are in the range of those previously obtained for $\delta^{34} \mathrm{~S}$ measurement by MC-ICPMS (0.1-0.5\%0). ${ }^{11-15}$
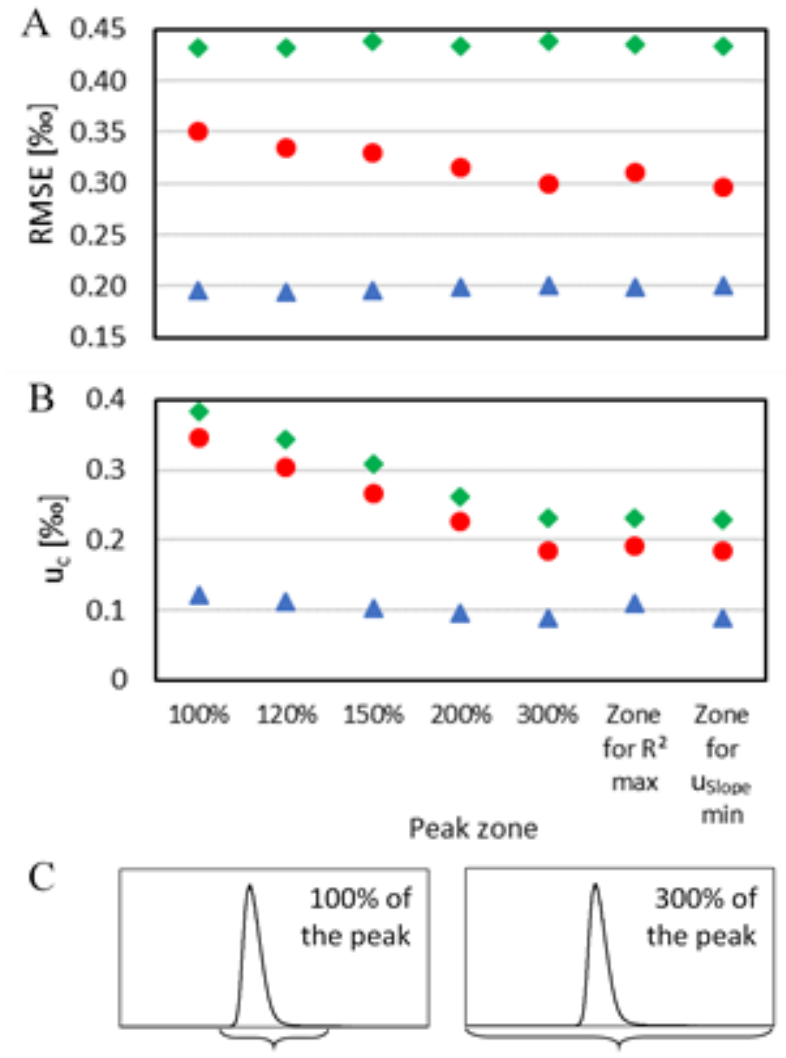

Figure 4. Determination of (A) RMSE and (B) mean combined uncertainty $\left(\mathrm{u}_{\mathrm{c}}\right)$ of $\delta^{34} \mathrm{~S}$ obtained for sulfite $(\boldsymbol{\Delta})$, sulfate $(\bullet)$ and thiosulfate $(\diamond)$ according to the peak zone selected for LRS calculation: values from 100 to $300 \%$ represent the peak zone selected as presented in figure C; "Zone for $\mathrm{R}^{2}$ max" refers to the peak zone required to have the highest $\mathrm{R}^{2}$ of the linear function and "Zone for uslope min" refers to the peak zone required to have the lowest slope standard deviation of the linear function.

Analytical Validation by Analysis of Synthetic and Environmental Samples. The developed procedure for simultaneously measuring $\delta^{34} \mathrm{~S}$ in sulfite, sulfate and thiosulfate was applied to synthetic solutions (pure salts in water, mineralized certified reference materials IAEA-S3 and IAEA-S4 and mineralized in-house material $\mathrm{H}_{3} \mathrm{NO}_{3} \mathrm{~S}$ ) and environmental water samples described elsewhere. ${ }^{22}$ 
All samples were diluted in the mobile phase to a final concentration of $10 \mu \mathrm{g} / \mathrm{g}$ of S per anion and TMSO was added at the same concentration. The results were then compared to the reported $\delta^{34} \mathrm{~S}$ values. As shown in Figure 5, the measured values were in good agreement (within $0.5 \% 0$ ) with reported values for all samples and all anions except for some of the environmental water samples for which, the $\delta^{34} S$ values measured by LC-MC-ICPMS appeared higher than the reported ones (more details in Table S-2). Such differences could be blamed on the extremely high $\mathrm{Na}^{+}$content relative to $\mathrm{SO}_{4}{ }^{2-}$ concentration in those samples, the $\left[\mathrm{Na}^{+}\right] /\left[\mathrm{SO}_{4}{ }^{2-}\right]$ mass ratio being systematically greater than 10 . Such matrix effect was also observed by Hanousek et al., Lin et al. and Liu et al. for the direct measurement of sulfate in water by MC-ICPMS. ${ }^{12,32,33}$ Hanousek et al. ${ }^{12}$ indicated that the addition of $\mathrm{Na}^{+}$caused a significant decrease in $\delta^{34} \mathrm{~S}$. In our case, we observed an increase in $\delta^{34} S$ due to the online anionic separation and internal standardization. Indeed, $\mathrm{Na}^{+}$ eluted in the dead volume together with the TMSO (cation) used for $\delta^{34}$ S measurement, so this process likely causes the decrease in ${ }^{34} \mathrm{~S} /{ }^{32} \mathrm{~S}$ of TMSO and consequently the $\delta^{34} \mathrm{~S}$ overestimation observed for sulfate. It is worth stressing, however, that it is rare to find $\left[\mathrm{Na}^{+}\right] /\left[\mathrm{SO}_{4}{ }^{2-}\right]$ mass ratios greater than 10 in modern seawater, rivers and aquifers. ${ }^{34-37}$ Estimation of the effect of sulfur concentration on the combined uncertainty was attempted by diluting ammonium sulfate to $1 \mu \mathrm{g} \mathrm{S} / \mathrm{g}$ and by applying reanalysis. The obtained value of $\delta^{34} \mathrm{~S}$ was $2.74 \pm 0.37 \%$, showing a slight increase relative to the $u_{c}$ of $0.18 \%$ obtained for the same anion at $10 \mu \mathrm{g} \mathrm{S} / \mathrm{g}$. Reproducibility was estimated by analyzing Solution 1 in different analytical sessions $(n=7)$. The following results were obtained: $\delta^{34} S_{\text {Sulfite- } 1}=6.00 \pm 0.26 \% 0 ; \delta^{34}$ S $_{\text {Sulfate- } 1}=2.58$ $\pm 0.26 \%$; and $\delta^{34} \mathrm{~S}_{\text {Thiosulfate- }}=4.33 \pm 0.50 \%$. These results are in agreement with the reproducibility typically obtained (0.1-1\%o) for $\delta^{34}$ S by MC-ICPMS. ${ }^{13-15,32,33}$

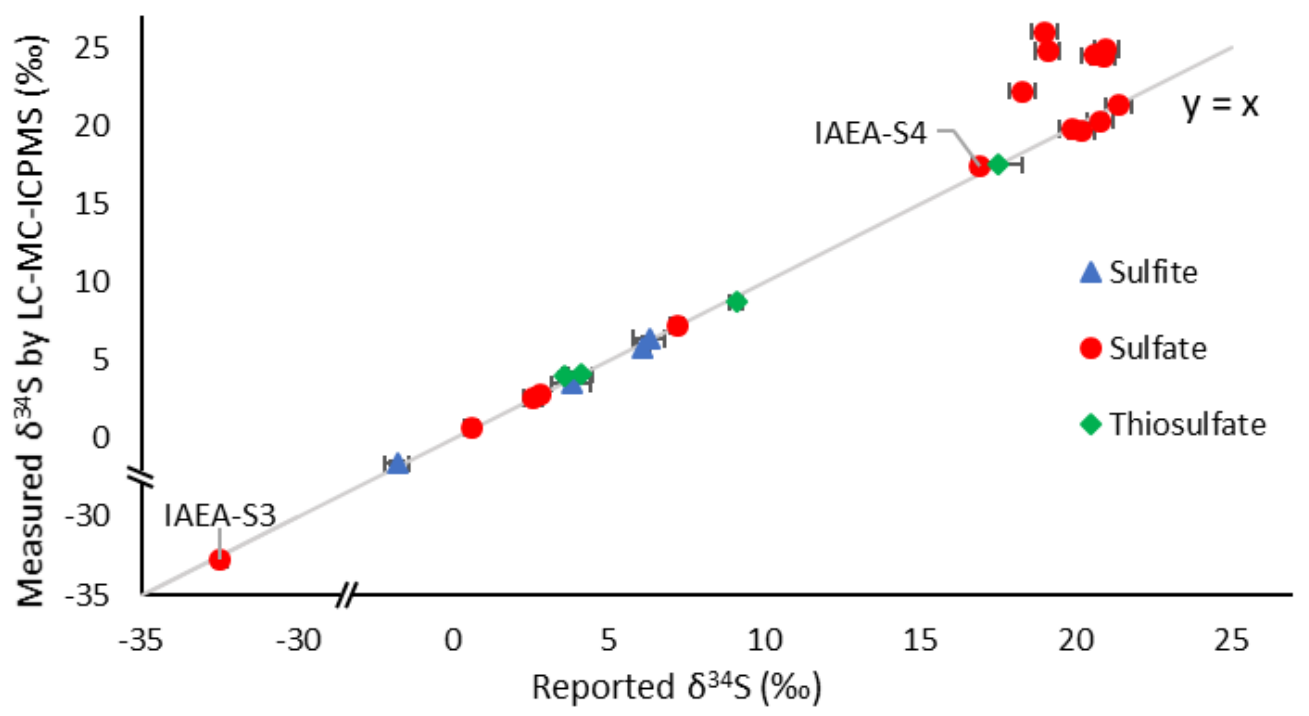

Figure 5. $\delta^{34}$ S for Measured Samples Obtained in this Work Compared with Reported Values. For LC-MC-ICPMS measurements, solutions and samples were diluted in the mobile phase to a final concentration of $10 \mu \mathrm{g} / \mathrm{g}$ of S per anion and TMSO was added at the same concentration. The given uncertainty for LC-MC-ICPMS measurements represents the combined uncertainty ( $\mathrm{u}_{\mathrm{c}}$ ) whereas for reported values it is the reported standard deviation. Reported $\delta^{34}$ S values for synthetic solutions $1,2,3,4$ and the in-house material $\mathrm{H}_{3} \mathrm{NO}_{3} \mathrm{~S}$ where determined by EA-IRMS in this study. Reported $\delta^{34} \mathrm{~S}$ values for IAEA-S3 and IAEA-S4 were determined by SF 6 -IRMS and MC-TIMS in ref $^{38}$ and by EA-IRMS in ref ${ }^{39}$, respectively. Reported $\delta^{34} \mathrm{~S}$ values for environmental waters where measured by EAIRMS in ref ${ }^{22}$. In some cases the uncertainty is smaller than the symbol. Complete numerical data is provided in Table S-2.

\section{CONCLUSIONS}

We have developed herein a simple, accurate and precise method for sulfur isotope composition $\left(\delta^{34} \mathrm{~S}\right)$ analysis of sulfite, sulfate and thiosulfate in a single run using LC-MCICPMS. We demonstrated the applicability of linear regression slope for sulfur isotope ratio calculations in transient signals and the further improvement of the results by using an algorithm that minimizes the slope standard deviation of the linear function. We compared mass bias correction by internal standardization, compound unspecific bracketing, compound specific bracketing and internal standardization combined with a correction by external calibration. The latter is the more accurate and robust method for mass bias correction. In addition, avoiding sample-standard bracketing enhances sample throughput and may be useful for sam- ples for which matrix matching remains difficult. The developed LC-MC-ICPMS method allows the analysis of $\delta^{34} \mathrm{~S}$ in sulfite, sulfate and thiosulfate in a single chromatographic run with a reproducibility better than $0.3 \%$ for sulfite and sulfate and better than $0.5 \%$ or for thiosulfate for $1 \mu \mathrm{g}$ of injected sulfur (per species); these reproducibilities are close to those obtained by EA-IRMS (0.1-0.5\%0). ${ }^{22,25,40}$ This online method considerably simplifies the analysis of environmental water samples since sample preparation and purification steps are no longer required and the time of analysis is reduced. Notably, only $1 \mu \mathrm{g}-\mathrm{S}$ is required, whereas the minimum amount for EA-IRMS is $33 \mu \mathrm{g}-\mathrm{S} .^{38}$

The application of our innovative methodology to synthetic solutions and environmental water samples shows the high accuracy achievable and points out the limitation of the method. Indeed, sample with $\left[\mathrm{Na}^{+}\right] /\left[\mathrm{SO}_{4}{ }^{2-}\right]$ greater than 10 
causes a significant bias in the measured $\delta^{34} \mathrm{~S}$, but such large $\left[\mathrm{Na}^{+}\right] /\left[\mathrm{SO}_{4}{ }^{2-}\right]$ is an extreme case. However, this limitation can be easily circumvented by selecting a different spiked standard, dithionate could be suitable as it will elutes after thiosulfate and will not coelute with cations ${ }^{27}$. Another alternative would be cation removal, this could be done using a suppressor unit after the ionic separation or by sample purification prior to analysis through an anion or cation exchange resin. ${ }^{12,14,16}$ We believe our work has strong potential and could be a basis for many applications because this $\delta^{34} \mathrm{~S}$ measurement method can be applied to most environmental water samples. Also, this method could be a powerful tool for studying oxidation and reduction processes of sulfur where intermediate valence sulfur anions such as sulfite and thiosulfate are formed.5,41,42

\section{ASSOCIATED CONTENT}

\section{Supporting Information}

Instrumental parameters, Operating conditions and Data acquisition parameters, Silicon isotope ratio variability, Peak definition for LRS calculations, $\delta^{34} \mathrm{~S}$ values of water samples. SI_1.pdf

\section{AUTHOR INFORMATION}

\section{Corresponding Author}

*E-mail: isabelle.lehecho@univ-pau.fr

\section{Author Contributions}

MM performed the experiments, analyzed the data, and wrote the manuscript, JIG co-designed and supervised the experiments, CP supervised the experiments and the PhD work, JRE supervised the experiments, ILH supervised the PhD work, designed the study and corrected the manuscript.

\section{Notes}

The authors declare no competing financial interest.

\section{ACKNOWLEDGMENTS}

The authors acknowledge the financial support of the Regional Council Nouvelle Aquitaine (Aquitraces project 2013120600113010973) and ISIFOR. Guilhem Hoareau is thanked for providing environmental water samples.

\section{REFERENCES}

(1) Kaplan, I. R.; Rittenberg, S. C. Microbiological Fractionation of Sulphur Isotopes. J. Gen. Microbiol. 1964, 34, 195212.

(2) Canfield, D. E. Isotope Fractionation by Natural Populations of Sulfate-Reducing Bacteria. Geochim. Cosmochim. Acta 2001, 65 (7), 1117-1124. https://doi.org/10.1016/S0016-7037(00)00584-6.

Knöller, K.; Vogt, C.; Feisthauer, S.; Weise, S. M.; Weiss, H.; Richnow, H.-H. Sulfur Cycling and Biodegradation in Contaminated Aquifers: Insights from Stable Isotope Investigations. Environ. Sci. Technol. 2008, 42 (21), 7807-7812. https://doi.org/10.1021/es800331p.

Stefánsson, A.; Keller, N. S.; Robin, J. G.; Ono, S. Multiple Sulfur Isotope Systematics of Icelandic Geothermal Fluids and the Source and Reactions of Sulfur in Volcanic Geothermal Systems at Divergent Plate Boundaries. Geochim. Cosmochim. Acta 2015, 165, 307-323. https://doi.org/10.1016/j.gca.2015.05.045.

(5) Leavitt, W. D.; Cummins, R.; Schmidt, M. L.; Sim, M. S.; Ono, S.; Bradley, A. S.; Johnston, D. T. Multiple Sulfur Isotope
Signatures of Sulfite and Thiosulfate Reduction by the Model Dissimilatory Sulfate-Reducer, Desulfovibrio Alaskensis Str. G20. Front. Microbiol. 2014, 5. https://doi.org/10.3389/fmicb.2014.00591.

(6) Gilhooly III, W. P.; Reinhard, C. T.; Lyons, T. W. A Comprehensive Sulfur and Oxygen Isotope Study of Sulfur Cycling in a Shallow, Hyper-Euxinic Meromictic Lake. Geochim. Cosmochim. Acta 2016, 189, 1-23. https://doi.org/10.1016/j.gca.2016.05.044.

(7) Fry, B.; Gest, H.; Hayes, J. M. Isotope Effects Associated with the Anaerobic Oxidation of Sulfite and Thiosulfate by the Photosynthetic Bacterium, Chromatium Vinosum. FEMS Microbiol. Lett. 1985, 27 (2), 227-232. https://doi.org/10.1111/j.1574-6968.1985.tb00672.x.

(8) Mayer, B.; Krouse, H. R. Chapter 26 - Procedures for Sulfur Isotope Abundance Studies. In Handbook of Stable Isotope Analytical Techniques; de Groot, P. A., Ed.; Elsevier: Amsterdam, 2004; pp 538-596. https://doi.org/10.1016/B978-044451114-0/50028-4.

Mayer, B.; Feger, K. H.; Giesemann, A.; Jäger, H.-J. Interpretation of Sulfur Cycling in Two Catchments in the Black Forest (Germany) Using Stable Sulfur and Oxygen Isotope Data. Biogeochemistry 1995, 30 (1), 31-58. https://doi.org/10.1007/BF02181039.

(10) David R. Lide, (Editor-in-Chief, National Institute of Standards and Technology). Handbook of Chemistry and Physics, 87th Edition. J. Am. Chem. Soc. 2007. https://doi.org/10.1021/ja069813z.

(11) Giner Martínez-Sierra, J.; Santamaria-Fernandez, R.; Hearn, R.; Marchante Gayón, J. M.; García Alonso, J. I. Development of a Direct Procedure for the Measurement of Sulfur Isotope Variability in Beers by MC-ICP-MS. J. Agric. Food Chem. 2010, 58 (7), 4043-4050. https://doi.org/10.1021/jf9019213.

(12) Hanousek, O.; Berger, T. W.; Prohaska, T. MC ICP-MS $\delta$ 34SVCDT Measurement of Dissolved Sulfate in Environmental Aqueous Samples after Matrix Separation by Means of an Anion Exchange Membrane. Anal. Bioanal. Chem. 2016, 408 (2), 399-407. https://doi.org/10.1007/s00216-015-9053-z.

(13) Yu, T.-L.; Wang, B.-S.; Shen, C.-C.; Wang, P.-L.; Yang, T. F.; Burr, G. S.; Chen, Y.-G. Improved Analytical Techniques of Sulfur Isotopic Composition in Nanomole Quantities by MC-ICP-MS. Anal. Chim. Acta 2017, 988, 34-40. https://doi.org/10.1016/j.aca.2017.08.012.

(14) Paris, G.; Sessions, A. L.; Subhas, A. V.; Adkins, J. F. MC-ICPMS Measurement of $\triangle 34 S$ and $\Delta 33 S$ in Small Amounts of Dissolved Sulfate. Chem. Geol. 2013, 345, 50-61. https://doi.org/10.1016/j.chemgeo.2013.02.022.

(15) Clough, R.; Evans, P.; Catterick, T.; Evans, E. H. $\Delta 34 \mathrm{~S}$ Measurements of Sulfur by Multicollector Inductively Coupled Plasma Mass Spectrometry. Anal. Chem. 2006, 78 (17), 6126-6132. https://doi.org/10.1021/ac060875h.

(16) Zakon, Y.; Halicz, L.; Gelman, F. Isotope Analysis of Sulfur, Bromine, and Chlorine in Individual Anionic Species by Ion Chromatography/Multicollector-ICPMS. Anal. Chem. 2014, 86 (13), 6495-6500. https://doi.org/10.1021/ac5010025.

(17) Epov, V. N.; Berail, S.; Jimenez-Moreno, M.; Perrot, V.; Pecheyran, C.; Amouroux, D.; Donard, O. F. X. Approach to Measure Isotopic Ratios in Species Using MulticollectorICPMS Coupled with Chromatography. Anal. Chem. 2010, 82 (13), 5652-5662. https://doi.org/10.1021/ac100648f.

(18) Fietzke, J.; Liebetrau, V.; Günther, D.; Gürs, K.; Hametner, K.; Zumholz, K.; Hansteen, T. H.; Eisenhauer, A. An Alternative Data Acquisition and Evaluation Strategy for Improved Isotope Ratio Precision Using LA-MC-ICP-MS Ap- 
plied to Stable and Radiogenic Strontium Isotopes in Carbonates. J. Anal. At. Spectrom. 2008, 23 (7), 955. https://doi.org/10.1039/b717706b.

(19) Yang, L.; Zhou, L.; Hu, Z.; Gao, S. Direct Determination of Si Isotope Ratios in Natural Waters and Commercial Si Standards by Ion Exclusion Chromatography Multicollector Inductively Coupled Plasma Mass Spectrometry. Anal. Chem. 2014, 86 (18), 9301-9308. https://doi.org/10.1021/ac5025396.

(20) Guéguen, F.; Isnard, H.; Nonell, A.; Vio, L.; Vercouter, T.; Chartier, F. Neodymium Isotope Ratio Measurements by LC-MC-ICPMS for Nuclear Applications: Investigation of Isotopic Fractionation and Mass Bias Correction. J Anal Spectrom 2015, 30, 443-452. https://doi.org/10.1039/C4JA00361F.

(21) Rodríguez-Castrillón, J. A.; García-Ruiz, S.; Moldovan, M.; García Alonso, J. I. Multiple Linear Regression and On-Line Ion Exchange Chromatography for Alternative $\mathrm{Rb}-\mathrm{Sr}$ and Nd-Sm MC-ICP-MS Isotopic Measurements. J. Anal. At. Spectrom. 2012, $27 \quad$ (4), 611-618. https://doi.org/10.1039/c2ja10274a.

(22) Pichat, A.; Hoareau, G.; Callot, J.-P.; Legeay, E.; Kavak, K. S.; Révillon, S.; Parat, C.; Ringenbach, J.-C. Evidence of Multiple Evaporite Recycling Processes in a Salt-Tectonic Context, Sivas Basin, Turkey. Terra Nova 2018, 30 (1), 40-49. https://doi.org/10.1111/ter.12306.

(23) Kragten, J. Tutorial Review. Calculating Standard Deviations and Confidence Intervals with a Universally Applicable Spreadsheet Technique. Analyst 1994, 119 (10), 2161 2165. https://doi.org/10.1039/AN9941902161.

(24) Quantifying Uncertainty in Analytical Measurements, 3rd Edition. 2012.

(25) Grassineau, N. V. High-Precision EA-IRMS Analysis of S and C Isotopes in Geological Materials. Appl. Geochem. 2006, 21 (5), 756-765. https://doi.org/10.1016/j.apgeochem.2006.02.015.

(26) Lin, L.-Y.; Jiang, S.-J. Determination of Sulfur Compounds in Water Samples by Ion Chromatography Dynamic Reaction Cell Inductively Coupled Plasma Mass Spectrometry. J. Chin. Chem. Soc. 2009, 56 (5), 967-973. https://doi.org/10.1002/jccs.200900141.

(27) O'Reilly, J. W.; Dicinoski, G. W.; Shaw, M. J.; Haddad, P. R. Chromatographic and Electrophoretic Separation of Inorganic Sulfur and Sulfur-Oxygen Species. Anal. Chim. Acta 2001, 432 (2), 165-192. https://doi.org/10.1016/S00032670(00)01389-1.

(28) Guéguen, F.; Nonell, A.; Isnard, H.; Vio, L.; Chartier, F. MultiElemental Gd, Eu, Sm, Nd Isotope Ratio Measurements by Liquid Chromatography Coupled to MC-ICPMS with Variable Faraday Cup Configurations during Elution. Talanta 2017, 162, 278-284. https://doi.org/10.1016/j.talanta.2016.10.030.

(29) Karasinski, J.; Bulska, E.; Wojciechowski, M.; Krata, A. A.; Halicz, L. On-Line Separation of Strontium from a Matrix and Determination of the Sr/Sr Ratio by Ion Chromatography/Multicollector-ICPMS. J Anal Spectrom 2016, 31, 1459-1463. https://doi.org/10.1039/C6JA00109B.

(30) Gourgiotis, A.; Manhès, G.; Martelat, B.; Isnard, H. Deconvolution of the Isotopic Drift in LC-MC-ICPMS Coupling: A New Tool for Studding Isotope Fractionation Induced by
Sample Introduction Techniques. J Anal Spectrom 2017. https://doi.org/10.1039/C6JA00418K.

(31) Albarède, F.; Telouk, P.; Blichert-Toft, J.; Boyet, M.; Agranier, A.; Nelson, B. Precise and Accurate Isotopic Measurements Using Multiple-Collector ICPMS. Geochim. Cosmochim. Acta 2004, 68 (12), 2725-2744. https://doi.org/10.1016/j.gca.2003.11.024.

(32) Lin, A.-J.; Yang, T.; Jiang, S.-Y. A Rapid and High-Precision Method for Sulfur Isotope $\delta{ }^{34}$ S Determination with a Multiple-Collector Inductively Coupled Plasma Mass Spectrometer: Matrix Effect Correction and Applications for Water Samples without Chemical Purification: Sulfur Isotope $\delta{ }^{34}$ S Determination by MC-ICP-MS. Rapid Commun. Mass Spectrom. 2014, 28 (7), 750-756. https://doi.org/10.1002/rcm.6838.

(33) Liu, C.; Bian, X.-P.; Yang, T.; Lin, A.-J.; Jiang, S.-Y. Matrix Effects of Calcium on High-Precision Sulfur Isotope Measurement by Multiple-Collector Inductively Coupled Plasma Mass Spectrometry. Talanta 2016, 151, 132-140. https://doi.org/10.1016/j.talanta.2016.01.013.

(34) Riley, J. P.; Chester, R. Introduction to Marine Chemistry; Academic Press: London, New York, 1971.

(35) Livingstone, D. A. Chemical Composition of Rivers and Lakes; Professional Paper; USGS Numbered Series 440-G; 1963.

(36) André, L.; Franceschi, M.; Pouchan, P.; Atteia, O. Using Geochemical Data and Modelling to Enhance the Understanding of Groundwater Flow in a Regional Deep Aquifer, Aquitaine Basin, South-West of France. J. Hydrol. 2005, 305 (1-4), 40-62. https://doi.org/10.1016/j.jhydrol.2004.08.027.

(37) Roy, R. N.; Roy, L. N.; Vogel, K. M.; Porter-Moore, C.; Pearson, T.; Good, C. E.; Millero, F. J.; Campbell, D. M. The Dissociation Constants of Carbonic Acid in Seawater at Salinities 5 to 45 and Temperatures 0 to $45^{\circ} \mathrm{C}$. Mar. Chem. 1993, 44 (2-4), 249-267. https://doi.org/10.1016/03044203(93)90207-5.

(38) Mann, J. L.; Vocke, R. D.; Kelly, W. R. Revised $\Delta 34$ S Reference Values for IAEA Sulfur Isotope Reference Materials S2 and S-3. Rapid Commun. Mass Spectrom. 2009, 23 (8), 1116-1124. https://doi.org/10.1002/rcm.3977.

(39) Qi, H. P.; Coplen, T. B. Evaluation of the 34S/32S Ratio of Soufre de Lacq Elemental Sulfur Isotopic Reference Material by Continuous Flow Isotope-Ratio Mass Spectrometry. Chem. Geol. 2003, 199 (1), 183-187. https://doi.org/10.1016/S0009-2541(03)00075-5.

(40) Thomas, F.; Jamin, E.; Shimoo, K.; Nagao, J.; Osaki, Y.; Granier, C. The Use of Multi-Element Stable Isotope Analysis to Monitor the Origin of Chondroitin Sulfates: Monitoring the Origin of Chondroitin Sulfates. Rapid Commun. Mass Spectrom. 2011, 25 (17), 2533-2537. https://doi.org/10.1002/rcm.5159.

(41) Jørgensen. The Sulfur Cycle of Freshwater Sediments: Role of Thiosulfate. Limnol. Oceanogr. 1990, 35 (6), 13291342. https://doi.org/10.4319/lo.1990.35.6.1329.

(42) Zhang, J.-Z.; Millero, F. J. The Products from the Oxidation of H2S in Seawater. Geochim. Cosmochim. Acta 1993, 57 (8), 1705-1718. https://doi.org/10.1016/00167037(93)90108-9. 
For Table of Contents Only

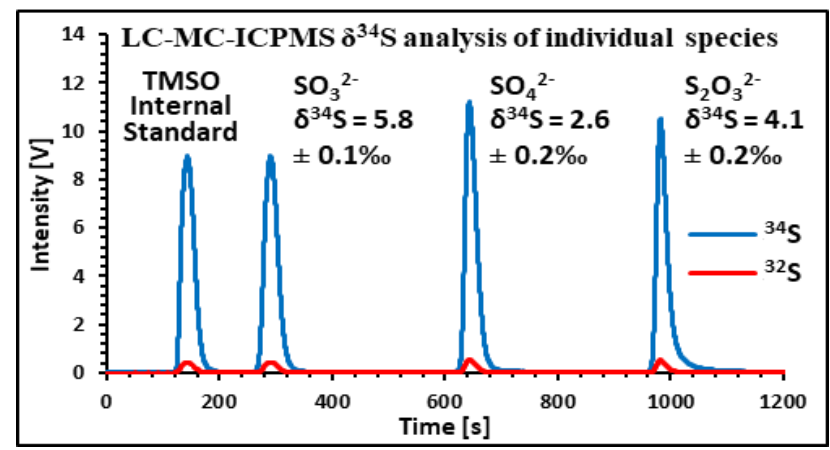

